OPEN ACCESS

Edited by:

Boqiang Li,

Institute of Botany (CAS), China

Reviewed by:

Jun Tian,

Jiangsu Normal University, China

Soner Soylu,

Mustafa Kemal University, Turkey

*Correspondence: Xingfeng Shao shaoxingfeng@nbu.edu.cn

Specialty section:

This article was submitted to

Food Microbiology,

a section of the journal

Frontiers in Microbiology

Received: 06 September 2017 Accepted: 27 September 2017

Published: 12 October 2017

Citation:

$X U$ J, Shao $X$, Wei Y, Xu F and Wang $H$ (2017) iTRAQ Proteomic Analysis Reveals That Metabolic Pathways Involving Energy Metabolism Are Affected by Tea Tree Oil in Botrytis cinerea. Front. Microbiol. 8:1989. doi: 10.3389/fmicb.2017.01989

\section{iTRAQ Proteomic Analysis Reveals That Metabolic Pathways Involving Energy Metabolism Are Affected by Tea Tree Oil in Botrytis cinerea}

\author{
Jiayu Xu, Xingfeng Shao*, Yingying Wei, Feng Xu and Hongfei Wang \\ Department of Food Science and Engineering, Ningbo University, Ningbo, China
}

Tea tree oil (TTO) is a volatile essential oil obtained from the leaves of the Australian tree Melaleuca alternifolia by vapor distillation. Previously, we demonstrated that TTO has a strong inhibitory effect on Botrytis cinerea. This study investigates the underlying antifungal mechanisms at the molecular level. A proteomics approach using isobaric tags for relative and absolute quantification (iTRAQ) was adopted to investigate the effects of $\Pi \mathrm{T}$ on $B$. cinerea. A total of 718 differentially expression proteins (DEPs) were identified in TTO-treated samples, 17 were markedly up-regulated and 701 were significantly down-regulated. Among the 718 DEPs, 562 were annotated and classified into 30 functional groups by GO (gene ontology) analysis. KEGG (Kyoto Encyclopedia of Genes and Genomes) enrichment analysis linked 562 DEPs to 133 different biochemical pathways, involving glycolysis, the tricarboxylic acid cycle (TCA cycle), and purine metabolism. Additional experiments indicated that TTO destroys cell membranes and decreases the activities of three enzymes related to the TCA cycle. Our results suggest that TTO treatment inhibits glycolysis, disrupts the TCA cycle, and induces mitochondrial dysfunction, thereby disrupting energy metabolism. This study provides new insights into the mechanisms underlying the antifungal activity of essential oils.

Keywords: iTRAQ, proteomics, essential oil, Botrytis cinerea, antifungal

\section{INTRODUCTION}

Botrytis cinerea, one of the most destructive fungal pathogens, causing gray mold rot in a wide range of fresh fruits and vegetables. The resulting reduction in shelf life is responsible for enormous economic losses in the produce industry. Although chemical fungicides are widely used to control the incidence of the disease, this practice potentially introduces harmful substances into the food chain, and also selects for B. cinerea strains with increased drug resistance (Brul and Coote, 1999; Leroux et al., 2002). These limitations provide a strong stimulus to explore safer and more effective antifungal agents. Essential oils are promising natural substitutes that offer disease control by inhibiting pathogen growth (Prakash et al., 2012). For example, the essential oils of Angelica archangelica L. (Apiaceae) roots and Solidago canadensis L. have been characterized and tested in vitro as antifungal agents against B. cinerea (Fraternale et al., 2014; Liu et al., 2016). Lemongrass essential oil significantly reduces the incidence of $B$. cinerea and prolongs the shelf-life and sensory properties of frozen mussels and vegetables (Abdulazeez et al., 2016). Essential oils of aromatic plants, which belong to the Lamiacea family such as origanum (Origanum syriacum L. var. bevanii), 
lavender (Lavandula stoechas L. var. stoechas) and rosemary (Rosmarinus officinalis L.), have been reported to cause considerable morphological degenerations of the fungal hyphae of $B$. cinerea and suppress in vivo disease development on tomato against B. cinerea (Soylu et al., 2010).

Tea tree oil (TTO) is a volatile natural plant essential oil obtained from the leaves of the Australian tree Melaleuca alternifolia by vapor distillation (Homer et al., 2000). The oil exhibits a broad spectrum of antimicrobial activities against a variety of bacteria, fungi, and virus (Carson et al., 2006; Miao et al., 2016). Growth and metabolic activity of Escherichia coli and Candida albicans are inhibited after treatment with TTO (Gustafson et al., 1998; Bona et al., 2016). Our previous studies showed that TTO treatment effectively inhibits spore germination and mycelial growth of $B$. cinerea, modifies its morphology and cellular ultrastructure, and controls gray mold on strawberry and cherry fruits (Shao et al., 2013a; Li et al., 2017a). TTO's antifungal mechanism in B. cinerea involves the loss of membrane integrity and the subsequent release of intracellular compounds, probably due in part to changes in membrane fatty acid and ergosterol composition (Shao et al., 2013b; Li et al., 2017a). TTO also causes mitochondrial damage in $B$. cinerea, disrupting the tricarboxylic acid (TCA) cycle and leading to the accumulation of reactive oxygen species (ROS) (Li et al., 2017b). Metabolomic analysis by quadrupole time-offlight mass spectrometer was consistent with these results $(\mathrm{Xu}$ et al., 2017). However, the molecular mechanisms underlying the effects of TTO against $B$. cinerea have not yet been associated with specific proteins.

Proteomics can be used to study the changes in protein levels under stress conditions in great detail (Franco et al., 2013), and has been applied to investigate the mode of action of the antimicrobial agent apidaecin IB against membrane proteins in E. coli cells (Zhou and Chen, 2011). Other studies have revealed that proteins related to energy and DNA metabolism, and amino acid biosynthesis are down-regulated in E. coli JK-17 in the presence of rose flower extract (Cho and Oh, 2011). Syzygium aromaticum essential oil perturbs the expression of virulencerelated genes involved in the synthesis of serine protease, flagella, and lipopolysaccharide in Campylobacter jejuni (Kovács et al., 2016). In this study, we conducted a proteomics analysis using isobaric tags for relative and absolute quantification (iTRAQ) to study $B$. cinerea to identify proteins and potential mechanisms underlying the antifungal activity of TTO.

\section{MATERIALS AND METHODS}

\section{B. cinerea Growth and Exposure to TTO}

Highly virulent $B$. cinerea (ACCC 36028) was purchased from the Agricultural Culture Collection of China and grown at $25^{\circ} \mathrm{C}$ on potato dextrose agar (PDA, containing $1 \mathrm{~L}$ potato liquid, $20 \mathrm{~g} / \mathrm{L}$ glucose, and $15 \mathrm{~g} / \mathrm{L}$ agar) before use. TTO was purchased from Fuzhou Merlot Lotus Biological Technology Company (Fujian Province, China). The primary components of TTO are terpinen4-ol (37.11\%), $\gamma$-terpinene (20.65\%), $\alpha$-terpinene (10.05\%), 1, 8cineole $(4.97 \%)$, terpinolene (3.55\%), $\rho$-cymene $(2.14 \%)$, and $\alpha$ terpineol $(3.82 \%)$, as specified by the supplier. $B$. cinerea cultures were maintained on PDA at $25^{\circ} \mathrm{C}$ for 3 days. Spore suspensions were harvested by adding $10 \mathrm{~mL}$ sterile $0.9 \% \mathrm{NaCl}$ solution to each petri dish and then gently scraping the mycelial surface three times with a sterile L-shaped spreader to free the spores. The spore suspension was adjusted using a hemocytometer to $5 \times 10^{6}$ spores/mL. One milliliter suspension was inoculated into $250 \mathrm{~mL}$ flasks containing $150 \mathrm{~mL}$ sterile potato dextrose broth medium and cultured at $25^{\circ} \mathrm{C}$ on a rotary shaker at 150 revolutions per minute for 3 days. Before mycelia were harvested, TTO was added to the medium to a final concentration of $5 \mathrm{~mL} / \mathrm{L}$, and cultures incubated for another $2 \mathrm{~h}$ (Xu et al., 2017). Mycelia were collected and rinsed three times with $0.1 \mathrm{M}$ phosphate buffered saline (PBS) ( $\mathrm{pH} 7.4$ ). Samples were stored at $-80^{\circ} \mathrm{C}$. Cultures without TTO were used as a control. Three samples were prepared in parallel for each condition.

\section{Protein Extraction}

Approximately $200 \mathrm{mg}$ of frozen mixed mycelium from control or TTO treated cultures was ground into powder in liquid nitrogen and suspended in $25 \mathrm{~mL} 10 \%(\mathrm{v} / \mathrm{v})$ trichloroacetic acid in acetone containing $65 \mathrm{mM}$ dithiothreitol (DTT). The suspension was vortexed and incubated at $-20^{\circ} \mathrm{C}$ for $2 \mathrm{~h}$, centrifuged at $12,000 \times \mathrm{g}$ for $45 \mathrm{~min}$ at $4^{\circ} \mathrm{C}$, and the supernatant discarded. The precipitate was rinsed three times with chilled acetone. The pellet was vacuum dried and dissolved in lysis buffer (4\% SDS, $100 \mathrm{mM}$ Tris- $\mathrm{HCl}, 100 \mathrm{mM}$ DTT, pH 8.0). After incubation for $5 \mathrm{~min}$ in boiling water, the suspension was sonicated on ice at $50 \mathrm{~W}$ for $5 \mathrm{~min}$. The crude extract was incubated in boiling water again for $5 \mathrm{~min}$, and clarified by centrifugation at $14,000 \times \mathrm{g}$ for $40 \mathrm{~min}$ at $20^{\circ} \mathrm{C}$. To digest protein in the supernatant, $200 \mu \mathrm{L}$ UA buffer $(8 \mathrm{M}$ urea, $150 \mathrm{mM}$ Tris- $\mathrm{HCl}, \mathrm{pH}$ 8.5) was added and the mixture was centrifuged at $14,000 \times \mathrm{g}$ for $30 \mathrm{~min}$ at room temperature. This step was repeated three times. Subsequently, $100 \mu \mathrm{L} 50 \mathrm{mM}$ iodoacetamide (IAM) was added, the samples were incubated for $30 \mathrm{~min}$ in darkness, and then centrifuged at $14,000 \times \mathrm{g}$ for $30 \mathrm{~min}$ at room temperature. The precipitate was resuspended in $100 \mu \mathrm{L}$ UA buffer and samples were centrifuged at 14,000 $\times \mathrm{g}$ for $30 \mathrm{~min}$ at room temperature. $100 \mu \mathrm{L}$ dissolution buffer was added, followed by centrifugation at 14,000 $\times \mathrm{g}$ for $30 \mathrm{~min}$ at room temperature. This step was repeated three times. The supernatant was removed, the pellet was dissolved in $40 \mu \mathrm{L}$ trypsin buffer, incubated at $37^{\circ} \mathrm{C}$ for $18 \mathrm{~h}$, and clarified by centrifugation at $14,000 \times \mathrm{g}$ for $30 \mathrm{~min}$ at room temperature. Finally, $40 \mu \mathrm{L} 25 \mathrm{mM}$ dissolution buffer was added and samples were centrifuged at $14,000 \times \mathrm{g}$ for $30 \mathrm{~min}$ at room temperature. The supernatant was transferred to a new tube and quantified with the Bradford assay using BSA as the standard, and SDS-PAGE was performed to verify protein quality.

\section{iTRAQ Labeling and Strong Cation Exchange (SCX) Fractionation}

iTRAQ labeling was performed according to the manufacturer's instructions. Peptides were prepared using the 8-plex iTRAQ labeling kit (AB Sciex, CA, USA). Control replicates were labeled with reagents 113,114 , and 115 , and the TTO treatment 
A

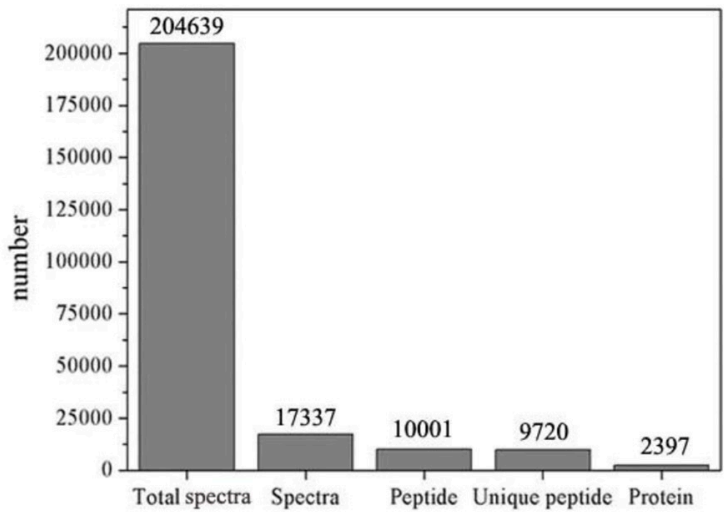

C

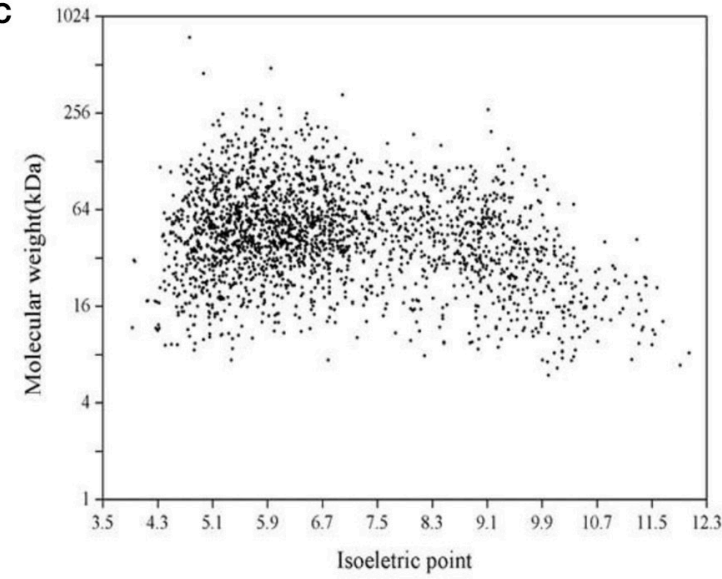

B

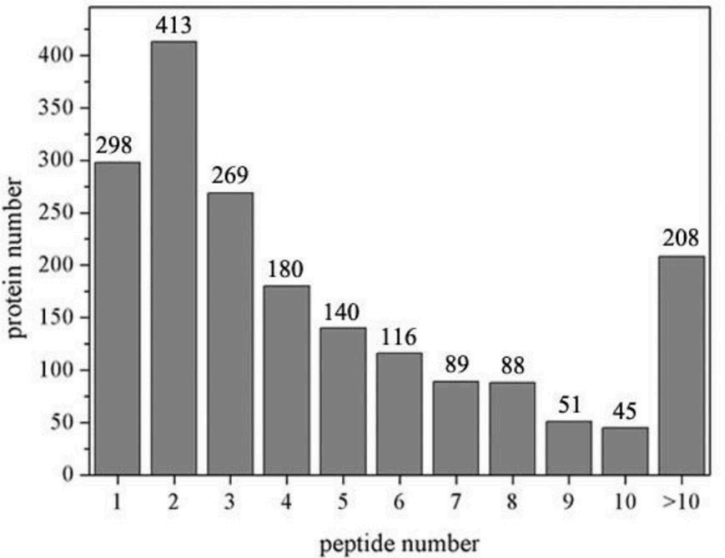

D

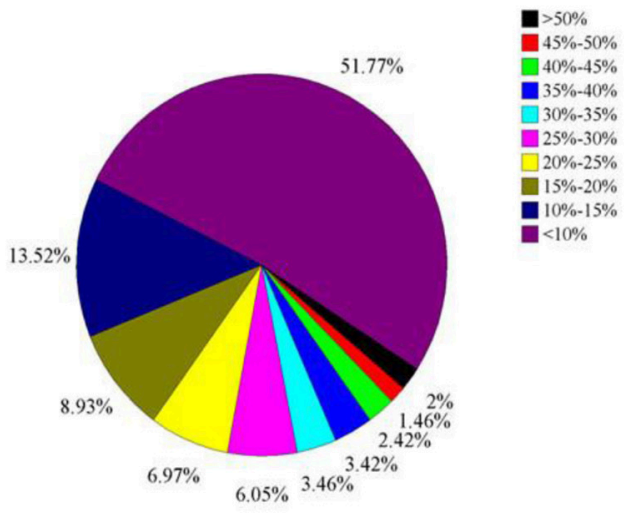

FIGURE 1 | Summary of iTRAQ results. (A), total spectra, matched spectra, matched peptides, unique peptides, and identified proteins. (B), number of peptides associated with identified proteins. (C), molecular weights vs. isoelectric points, as calculated from protein sequences. (D), sequence coverage for identified proteins.

replicates were labeled with reagents 116,117 , and 118 . The labeled peptide mixtures were pooled and dried by vacuum centrifugation.

The labeled peptide mixtures were dissolved in $3 \mathrm{~mL}$ buffer $\mathrm{A}$ ( $10 \mathrm{mM} \mathrm{KH}_{2} \mathrm{PO}_{4}$ in 25\% acetonitrile, $\mathrm{pH} 3.0$ ) and loaded onto a polysulfoethyl $4.6 \times 100 \mathrm{~mm}$ column $(5 \mu \mathrm{m}, 200 \AA$, PolyLC, Inc., Maryland, USA). The peptides were eluted at a flow rate of $1 \mathrm{~mL} / \mathrm{min}$ with a gradient of buffer A for $30 \mathrm{~min}, 5-70 \%$ buffer $\mathrm{B}\left(10 \mathrm{mM} \mathrm{KH}_{2} \mathrm{PO}_{4}, 500 \mathrm{mM} \mathrm{KCl}\right.$ in $25 \%$ acetonitrile, $\left.\mathrm{pH} 3.0\right)$ for $65 \mathrm{~min}$, and $70-100 \%$ buffer $\mathrm{B}$ for $80 \mathrm{~min}$. The eluted peptides were pooled into 10 fractions, desalted on C18 cartridges (Sigma), and vacuum-dried.

\section{LC-MS/MS Analysis}

For nano LC-MS/MS analysis, $10 \mu \mathrm{L}$ of supernatant from each fraction was injected into an Obitrap-Elite (ThermoFinnigan) equipped with an Easy nLC (Proxeon Biosystems, now Thermo Fisher Scientific). The mobile phase was a mixture of water containing $0.1 \%$ formic acid and acetonitrile with $0.1 \%$ formic acid isocratically delivered by a pump at a flowrate of $250 \mathrm{~nL} / \mathrm{min}$.
The elution gradient was: 0-105 min, 0-50\% B; 105-110 min, 50$100 \% \mathrm{~B} ; 110-120 \mathrm{~min}, 100 \% \mathrm{~B}$. The MS scanning range was $300-$ $1,800 \mathrm{~m} / \mathrm{z}$, MS resolution was 70,000, the number of scans range was 1 , and the dynamic exclusion time was $40 \mathrm{~s}$. The MS/MS activation type was HCD, the isolation window was $2 \mathrm{~m} / \mathrm{z}$, the MS/MS resolution was 17,500 , the normalized collision energy was $30 \mathrm{eV}$, and the underfill ratio was $0.1 \%$.

\section{Analysis of Differentially Expression Proteins}

For protein quantitation, one protein was required to contain at least two unique peptides. The quantitative protein ratios were weighted and normalized by the median ratio in Mascot (http://www.matrixscience.com). When differences in protein expression between TTO-treated and control groups were $>1.5$ fold or $<0.67$-fold, with $p<0.05$, the protein was considered to be differentially expressed.

\section{Bioinformatic Analysis}

Gene Ontology (GO) is a standardized gene function classification system that describes the properties of proteins 
TABLE 1 | The main differentially expressed proteins in B. cinerea after treatment with TTO.

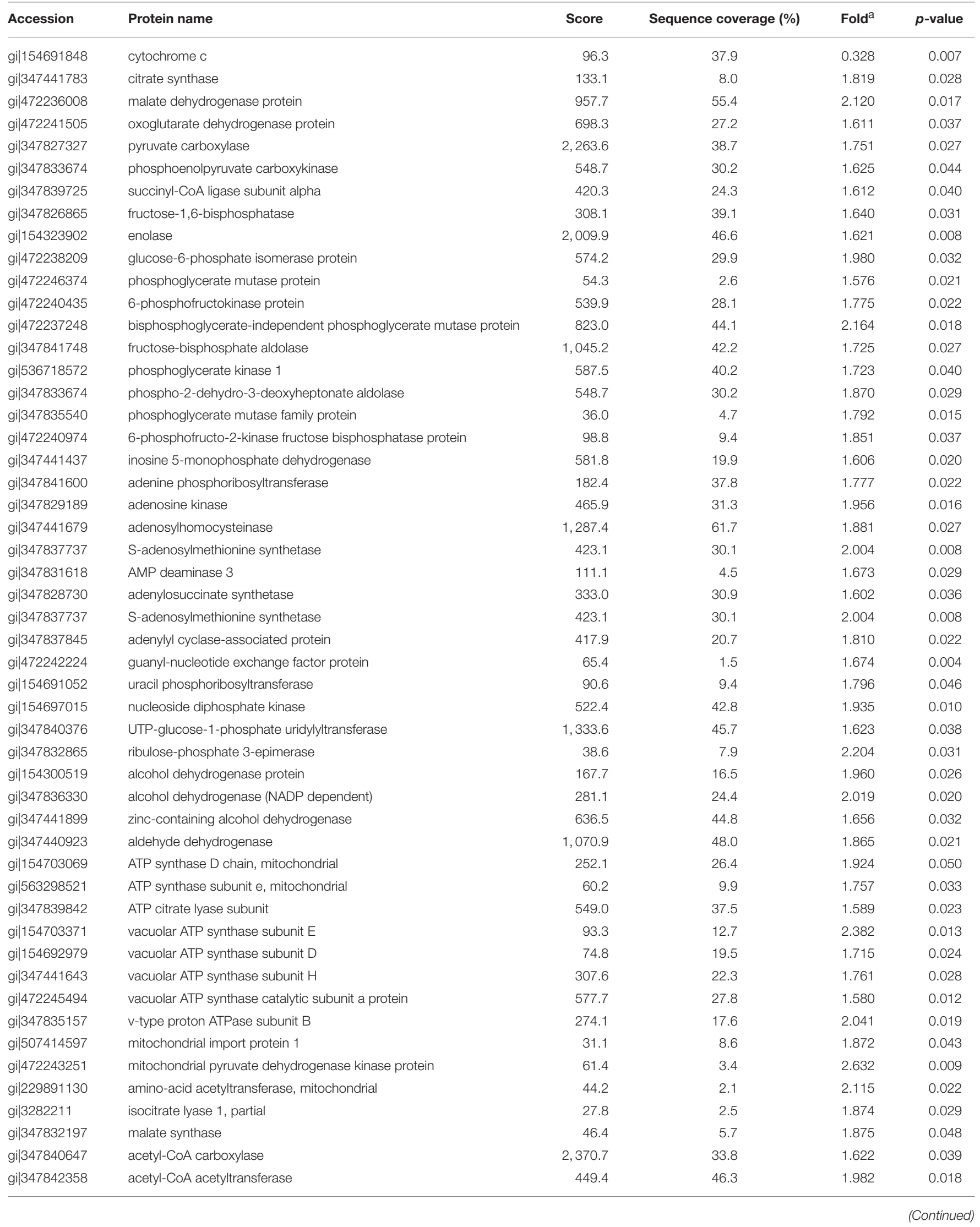


TABLE 1 | Continued

\begin{tabular}{|c|c|c|c|c|c|}
\hline Accession & Protein name & Score & Sequence coverage (\%) & Fold $^{a}$ & $p$-value \\
\hline gi|347841050 & fatty acid synthase & $1,414.5$ & 25.2 & 1.693 & 0.042 \\
\hline gi|472245418 & fatty acid synthase beta subunit dehydratase protein & $1,668.6$ & 24.8 & 1.567 & 0.045 \\
\hline gi|347841364 & NADP-specific glutamate dehydrogenase & $1,138.8$ & 46.9 & 1.840 & 0.021 \\
\hline gi|347827914 & homocitrate synthase & 454.5 & 39.0 & 1.501 & 0.031 \\
\hline gi|347837008 & homoserine kinase & 190.1 & 28.7 & 1.920 & 0.042 \\
\hline gi|347836521 & GABA transaminase & 483.9 & 27.7 & 1.544 & 0.018 \\
\hline gi|472242205 & aspartate aminotransferase protein & 385.8 & 26.1 & 1.837 & 0.048 \\
\hline gi|347841990 & tryptophan synthase & 611.0 & 28.3 & 1.542 & 0.024 \\
\hline gi|347832506 & threonine synthase & 348.4 & 16.4 & 1.560 & 0.047 \\
\hline gi|154692095 & cysteine synthase & 292.8 & 25.0 & 1.589 & 0.028 \\
\hline gi|347833148 & glutamine synthetase & 484.0 & 26.9 & 1.778 & 0.015 \\
\hline gi|347839014 & histidine biosynthesis protein & 184.6 & 9.3 & 1.840 & 0.027 \\
\hline gi|347828253 & dihydrodipicolinate synthetase family protein & 518.7 & 28.0 & 1.869 & 0.013 \\
\hline gi|347836881 & D-3-phosphoglycerate dehydrogenase & 656.4 & 25.5 & 1.758 & 0.018 \\
\hline gi|472242394 & saccharopine dehydrogenase protein & 338.7 & 36.2 & 1.743 & 0.039 \\
\hline gi|347441047 & glycine dehydrogenase & 286.9 & 12.3 & 1.708 & 0.029 \\
\hline gi|507414630 & C-1-tetrahydrofolate synthase & 905.4 & 31.2 & 1.737 & 0.031 \\
\hline gi|347831191 & glutamate carboxypeptidase protein & 298.0 & 23.2 & 1.977 & 0.020 \\
\hline gi|347841903 & methionine aminopeptidase 1 & 221.2 & 20.3 & 2.040 & 0.021 \\
\hline gi|332313356 & methionine aminopeptidase 2 & 73.1 & 10.3 & 2.044 & 0.027 \\
\hline gi|347829817 & serine/threonine protein kinase & 32.6 & 4.4 & 1.693 & 0.037 \\
\hline gi|472244536 & glutamate-cysteine ligase protein & 61.6 & 3.6 & 1.698 & 0.037 \\
\hline gi|347829487 & 5-methyltetrahydropteroyltriglutamate-homocysteine methyltransferase & $2,013.2$ & 41.1 & 2.505 & 0.004 \\
\hline gi|347836712 & glycine cleavage system $\mathrm{H}$ protein & 116.0 & 22.0 & 1.982 & 0.025 \\
\hline gi|472236211 & amino acid permease protein & 39.7 & 4.0 & 1.999 & 0.031 \\
\hline gi|347830997 & peptide methionine sulfoxide reductase & 82.8 & 20.5 & 1.919 & 0.029 \\
\hline gi|472243795 & aromatic-I-amino-acid decarboxylase protein & 287.6 & 12.1 & 1.936 & 0.015 \\
\hline gi|347833024 & lysine decarboxylase-like protein & 79.7 & 8.6 & 1.585 & 0.033 \\
\hline gi|472246546 & glutathione-dependent formaldehyde dehydrogenase & 587.5 & 48.7 & 1.666 & 0.043 \\
\hline gi|347840830 & NADH-cytochrome b5 reductase & 305.5 & 23.0 & 1.545 & 0.029 \\
\hline gi|347827019 & cytochrome P450 monooxygenase & 31.4 & 2.4 & 1.722 & 0.042 \\
\hline gi|125949746 & calcineurin & 194.3 & 12.4 & 1.777 & 0.023 \\
\hline gi|154289817 & chitin synthase & 129.2 & 4.7 & 1.555 & 0.023 \\
\hline gi|347840218 & sorbitol dehydrogenase & 28.3 & 2.9 & 1.706 & 0.028 \\
\hline gi|347440923 & aldehyde dehydrogenase & $1,070.9$ & 48.0 & 1.865 & 0.021 \\
\hline gi|347833737 & mitochondrial peroxiredoxin Prx1 & 42.8 & 7.6 & 1.856 & 0.044 \\
\hline gi|347828993 & antioxidant & 129.5 & 33.1 & 2.127 & 0.028 \\
\hline gi|347839043 & superoxide dismutase & 163.1 & 17.0 & 1.717 & 0.012 \\
\hline gi|166408944 & flavohemoglobin & 294.7 & 35.7 & 1.994 & 0.009 \\
\hline gi|347828340 & oxidoreductase & 305.1 & 14.93 & 2.119 & 0.045 \\
\hline gi|347841065 & nuclear control of ATPase protein & 84.7 & 4.7 & 0.219 & 0.001 \\
\hline gi|347836808 & heat shock protein 70 & $3,060.8$ & 53.2 & 1.750 & 0.014 \\
\hline gi|472242753 & 30 kda heat shock protein & 296.7 & 47.5 & 1.959 & 0.019 \\
\hline gi|347827157 & heat shock protein 90 & $1,603.7$ & 37.7 & 1.650 & 0.032 \\
\hline gi|347830903 & heat shock protein STI1 & 689.1 & 35.8 & 2.451 & 0.011 \\
\hline gi|347830415 & heat shock protein Hsp88 & $1,199.5$ & 34.3 & 1.817 & 0.020 \\
\hline gi|347833633 & heat shock protein & 748.3 & 34.3 & 1.999 & 0.020 \\
\hline gi|154288804 & short chain dehydrogenase & 105.9 & 20.7 & 2.142 & 0.005 \\
\hline gi|347840162 & translation initiation factor 3 & 284.6 & 46.8 & 1.905 & 0.031 \\
\hline gi|472245156 & eukaryotic translation initiation factor 3 subunit & 749.4 & 18.9 & 1.890 & 0.015 \\
\hline gi|229463757 & eukaryotic translation initiation factor 3 subunit $\mathrm{H}$ & 195.8 & 20.7 & 1.851 & 0.013 \\
\hline
\end{tabular}


TABLE 1 | Continued

\begin{tabular}{|c|c|c|c|c|c|}
\hline Accession & Protein name & Score & Sequence coverage (\%) & Fold $^{\mathrm{a}}$ & $p$-value \\
\hline gi|229501208 & eukaryotic translation initiation factor 3 subunit $\mathrm{K}$ & 232.7 & 33.5 & 1.751 & 0.044 \\
\hline gi|347841080 & eukaryotic translation initiation factor 2 subunit alpha & 193.5 & 17.1 & 1.574 & 0.030 \\
\hline gi|347840917 & actin-depolymerizing factor 1 & 519.9 & 53.6 & 1.959 & 0.018 \\
\hline gi|3182891 & actin & $1,055.4$ & 52.8 & 1.555 & 0.035 \\
\hline gi|347838304 & F-actin capping protein beta subunit isoforms 1 and 2 & 156.0 & 27.7 & 1.595 & 0.044 \\
\hline gi|205716451 & actin cytoskeleton-regulatory complex protein end 3 & 109.4 & 10.4 & 1.827 & 0.022 \\
\hline gi|347827283 & actin lateral binding protein & 691.2 & 50.3 & 2.621 & 0.002 \\
\hline gi|347441258 & myosin regulatory light chain cdc4 & 327.6 & 43.9 & 1.775 & 0.049 \\
\hline gi|347838471 & survival factor 1 & 321.9 & 28.4 & 1.608 & 0.038 \\
\hline gi|347826783 & transcription initiation factor subunit & 28.9 & 7.4 & 2.083 & 0.024 \\
\hline gi|347837746 & transcription factor CBF/NF-Y & 46.1 & 6.1 & 1.869 & 0.021 \\
\hline gi|347840266 & transcription factor $\mathrm{Zn}, \mathrm{C}_{2} \mathrm{H}_{2}$ & 50.5 & 1.7 & 3.407 & 0.003 \\
\hline gi|347837101 & EF-hand calcium-binding domain protein & 42.8 & 3.7 & 0.031 & 0.001 \\
\hline gi|472246130 & cell division control protein cdc 48 protein & $1,298.4$ & 40.7 & 1.654 & 0.021 \\
\hline gi|472235945 & cell lysis protein & 103.7 & 20.5 & 1.930 & 0.025 \\
\hline gi|206558271 & cell division cycle protein 123 & 38.6 & 3.9 & 1.809 & 0.050 \\
\hline gi|347828695 & apoptosis-inducing factor 3 & 267.7 & 17.2 & 2.290 & 0.003 \\
\hline gi|472242094 & thioredoxin protein & 388.6 & 51.4 & 2.634 & 0.003 \\
\hline gi|472244889 & sulfate adenylyltransferase protein & 328.9 & 25.8 & 1.858 & 0.011 \\
\hline gi|472242788 & proteasome component pre3 protein & 101.7 & 23.9 & 1.942 & 0.023 \\
\hline gi|347841691 & arp2/3 complex subunit Arc16 & 249.2 & 41.7 & 1.729 & 0.020 \\
\hline gi|154319207 & $26 S$ protease regulatory subunit 7 & 221.9 & 19.4 & 2.009 & 0.026 \\
\hline gi|347833025 & proteasome subunit alpha type 1 & 133.2 & 16.9 & 1.706 & 0.025 \\
\hline gi|347441407 & protein kinase $\mathrm{C}$ substrate & 282.5 & 18.1 & 1.703 & 0.028 \\
\hline gi|347827686 & sec14 cytosolic factor & 240.1 & 41.4 & 1.711 & 0.030 \\
\hline gi|347840528 & peptidyl-prolyl cis-trans isomerase D & 431.3 & 39.9 & 2.070 & 0.019 \\
\hline gi|563298153 & inorganic pyrophosphatase & 317.8 & 29.7 & 1.714 & 0.015 \\
\hline gi|347830035 & aldose 1-epimerase & 338.4 & 29.6 & 2.114 & 0.040 \\
\hline gi|347831189 & carbohydrate-Binding Module family 48 protein & 330.4 & 27.1 & 3.744 & 0.014 \\
\hline gi|347839149 & carbohydrate-Binding Module family 50 protein & 196.5 & 25.3 & 2.276 & 0.047 \\
\hline gi|347841295 & cystathionine beta-synthase & 416.0 & 26.0 & 1.790 & 0.031 \\
\hline gi|347842143 & diphosphomevalonate decarboxylase & 303.6 & 25.9 & 1.788 & 0.022 \\
\hline gi|347836348 & protein phosphatase PP2A regulatory subunit A & 414.1 & 21.1 & 1.576 & 0.045 \\
\hline gi|347838932 & class I/II aminotransferase & 340.3 & 23.9 & 1.844 & 0.015 \\
\hline gi|347831623 & amidophosphoribosyltransferase & $1,467.6$ & 20.8 & 1.573 & 0.025 \\
\hline gi|472236449 & enoyl- hydratase isomerase protein & 101.1 & 19.1 & 1.849 & 0.026 \\
\hline gi|472237246 & tubulin-specific chaperone c protein & 222.7 & 20.7 & 1.621 & 0.044 \\
\hline
\end{tabular}


TABLE 1 | Continued

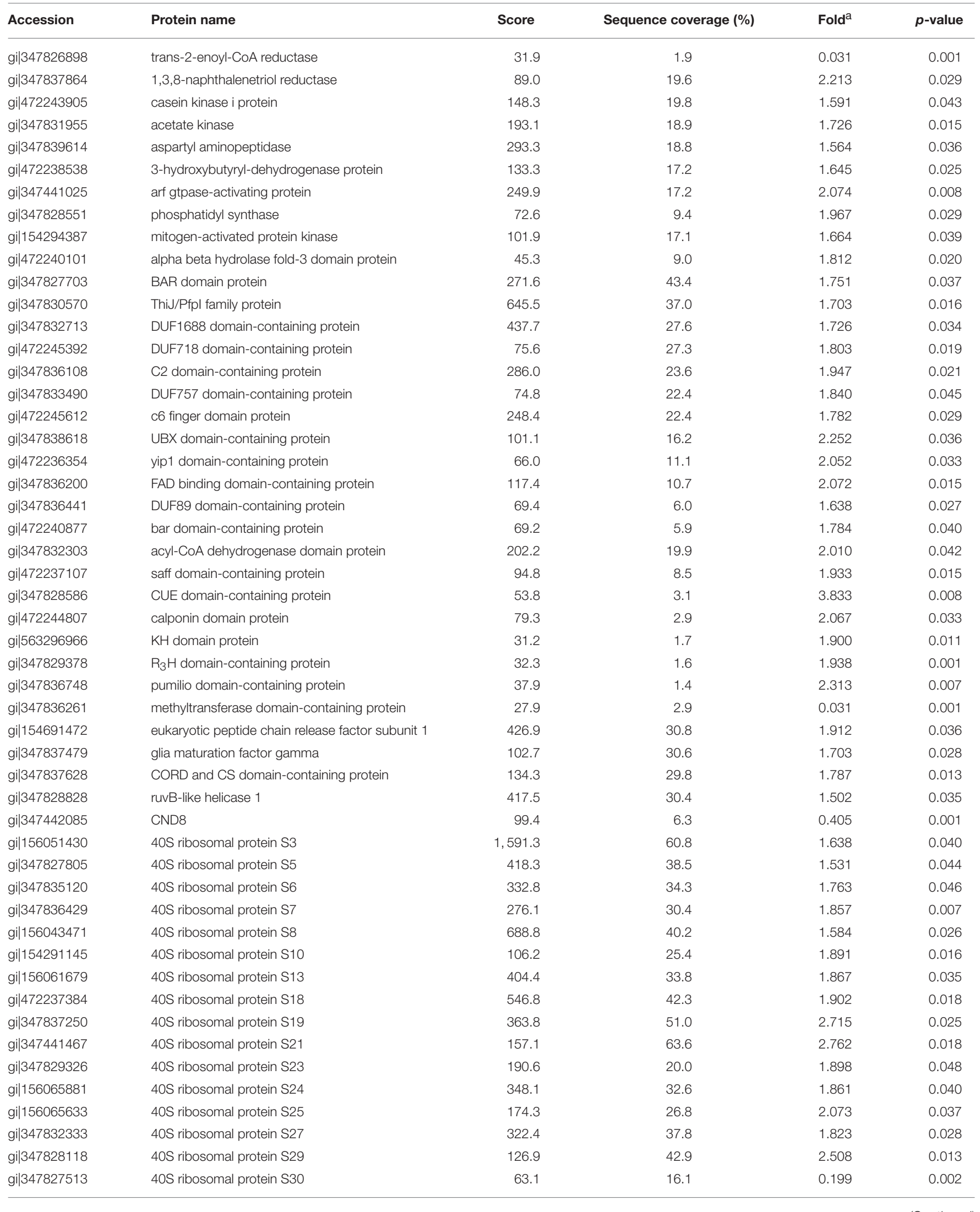


TABLE 1 | Continued

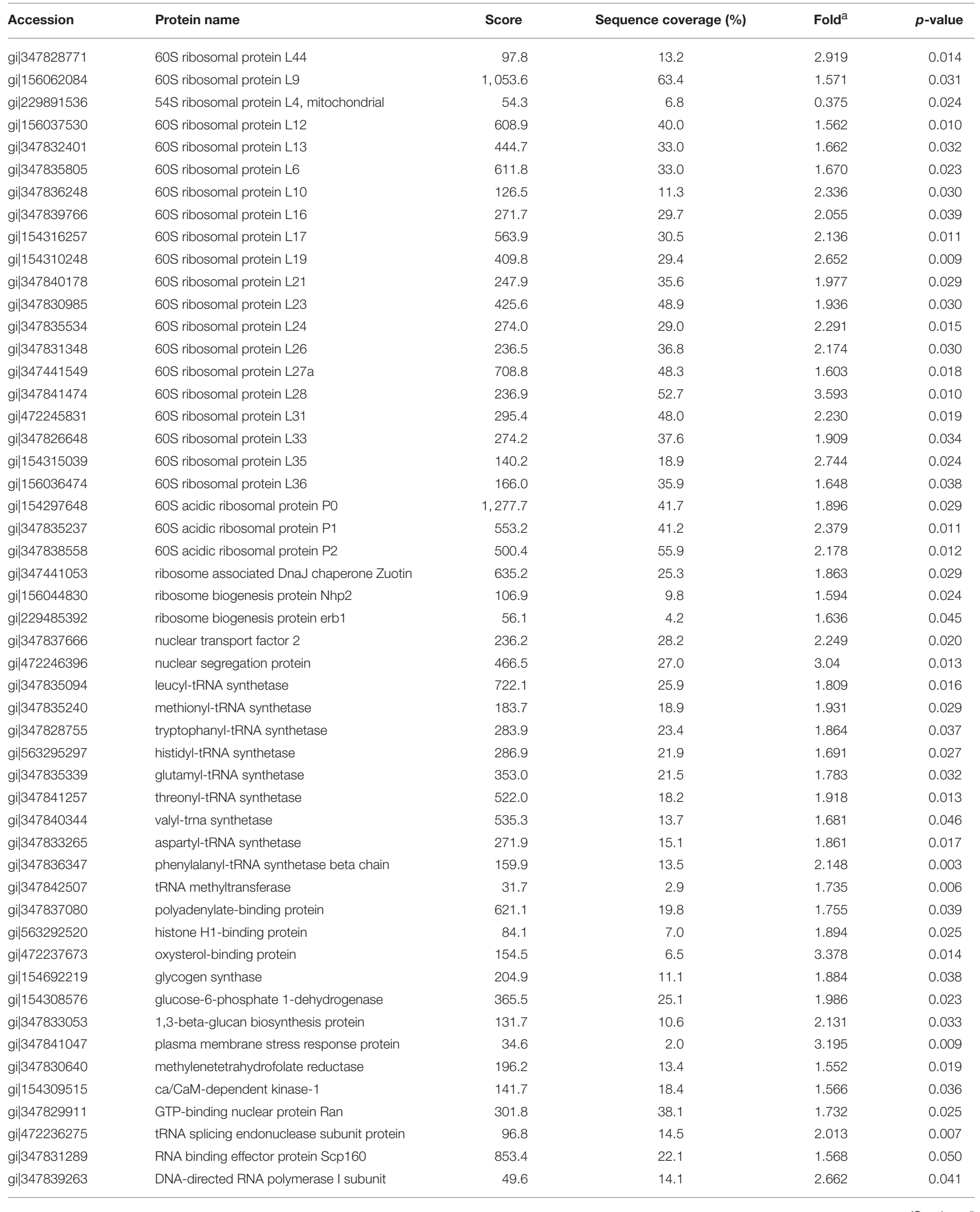


TABLE 1 | Continued

\begin{tabular}{|c|c|c|c|c|c|}
\hline Accession & Protein name & Score & Sequence coverage (\%) & Fold $^{a}$ & $p$-value \\
\hline gi|347441996 & HAD superfamily hydrolase & 203.1 & 32.5 & 1.599 & 0.041 \\
\hline gi|347840552 & ubiquitin carboxyl-terminal hydrolase & 362.9 & 27.1 & 1.976 & 0.026 \\
\hline gi|347837756 & ubiquitin-like protein SMT3 & 34.9 & 18.8 & 2.301 & 0.030 \\
\hline gi|472238757 & ubiquitin-activating enzyme e 11 protein & 489.3 & 17.3 & 1.665 & 0.016 \\
\hline gi|154695558 & ubiquitin-conjugating enzyme E2 & 36.3 & 7.5 & 1.579 & 0.042 \\
\hline gi|472241717 & ubiquitin thioesterase protein & 56.4 & 8.3 & 1.749 & 0.027 \\
\hline gi|347440894 & translocon beta subunit Sbh1 & 225.3 & 44.6 & 1.753 & 0.042 \\
\hline gi|472236180 & minor allergen alt a 7 protein & 282.3 & 47.8 & 2.844 & 0.005 \\
\hline gi|472235513 & anthranilate synthase component 2 protein & 392.7 & 20.7 & 1.590 & 0.029 \\
\hline gi|347833273 & nipsnap family protein & 154.3 & 19.9 & 1.633 & 0.026 \\
\hline gi|347832071 & phosphoglucomutase & $1,936.2$ & 53.1 & 1.896 & 0.017 \\
\hline gi|347829895 & phosphomannomutase & 182.7 & 21.5 & 1.854 & 0.028 \\
\hline gi|347832016 & $\mathrm{N}$-acetylglucosamine-phosphate mutase & 436.9 & 26.4 & 1.853 & 0.011 \\
\hline gi|347841616 & UDP-galactopyranose mutase & 549.0 & 33.1 & 2.149 & 0.020 \\
\hline gi|347841593 & UDP-N-acetylglucosamine pyrophosphorylase & 519.9 & 35.0 & 1.922 & 0.008 \\
\hline gi|472237006 & UDP-glucose 4-epimerase gal10 protein & 191.1 & 20.5 & 1.867 & 0.009 \\
\hline gi|347441001 & mannose-1-phosphate guanyltransferase alpha-a & 584.1 & 36.3 & 1.631 & 0.033 \\
\hline gi|472241485 & nad h-dependent $d$-xylose reductase xyl1 protein & 247.9 & 28.6 & 1.541 & 0.046 \\
\hline gi|347828612 & transketolase & $1,284.8$ & 41.2 & 2.020 & 0.013 \\
\hline gi|154321267 & phosphoketolase & 883.5 & 24.4 & 1.836 & 0.042 \\
\hline gi|347842358 & acetyl-CoA acetyltransferase & 449.4 & 46.3 & 1.982 & 0.018 \\
\hline gi|347830285 & phospho-2-dehydro-3-deoxyheptonate aldolase & 460.2 & 36.1 & 1.950 & 0.027 \\
\hline gi|347840715 & 3-isopropylmalate dehydratase & 593.0 & 29.8 & 1.519 & 0.019 \\
\hline gi|347440697 & cyanide hydratase/nitrilase & 353.7 & 17.0 & 2.551 & 0.012 \\
\hline gi|347832595 & aldo/keto reductase family oxidoreductase & 497.6 & 42.5 & 1.999 & 0.018 \\
\hline gi|154322845 & aldo/keto reductase & 327.8 & 28.9 & 1.724 & 0.044 \\
\hline gi|347838695 & nitroreductase family protein & 228.3 & 32.7 & 1.893 & 0.018 \\
\hline gi|154293270 & glucose 1-dehydrogenase & 263.4 & 27.8 & 1.636 & 0.043 \\
\hline
\end{tabular}

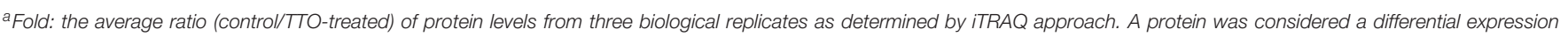
protein as it exhibited a $>1.5$-fold or $<0.67$-fold change and $P<0.05$.

using three attributes: biological process, molecular function, and cellular components (Ashburner et al., 2000). A GO analysis (http://www.geneontology.org) was conducted to assign functional annotations for differentially expression proteins (DEPs), and the Kyoto Encyclopedia of Genes and Genomes (KEGG) (http://www.genome.jp/kegg) was used to predict the primary metabolic and signal transduction pathways in which the identified DEPs are involved.

\section{Confocal Laser Scanning Microscopy}

To assess the effects of TTO on the cytoplasmic membranes of B. cinerea, confocal laser scanning microscopy (LSM 880, Carl Zeiss, Germany) was performed, using the fluorescent indicator propidium iodide (PI) (Sigma-Aldrich, USA) and a modified protocol (Lee and Kim, 2017). B. cinerea cells containing $4 \times 10^{6}$ spores/ml were added to each glass tube and incubated with TTO (final concentration $5 \mathrm{~mL} / \mathrm{L}$ ) with shaking at $200 \mathrm{rpm}$ at $25^{\circ} \mathrm{C}$ for $2 \mathrm{~h}$. The cells were washed and resuspended in $0.5 \mathrm{~mL} \mathrm{PBS}(\mathrm{pH}$ 7.4), stained with PI (10 $\mu \mathrm{M}$ final concentration) for $30 \mathrm{~min}$ at room temperature in the dark, and then washed twice with PBS.
Images were acquired using confocal laser scanning microscopy. The experiment was repeated three times.

\section{Measurement of Enzyme Activities Related to TCA Cycle}

Using the protocol described above (see Protein Extraction), ground mycelium was suspended in PBS ( $\mathrm{pH} 7.4)$ and centrifuged at $10,000 \times \mathrm{g}$ for $10 \mathrm{~min}$ at $4^{\circ} \mathrm{C}$. Enzyme activities were measured in the supernatant for malate dehydrogenase $(\mathrm{MDH})$, citrate synthase (CS), and oxoglutarate dehydrogenase (OGDH), using kits purchased from Nanjing Jiancheng Bioengineering Institute (Nanjing, Jiangsu, China), following the manufacturer's instructions. Protein concentration was determined using a method based on the (Bradford, 1976) assay. $\mathrm{MDH}$ activity was calculated as $\mu \mathrm{mol}$ of NAD reduced per minute per $\mathrm{mg}$ of protein (U/mg protein). One unit of CS activity was defined as the amount of enzyme that produces $1 \mu \mathrm{mol}$ of citric acid per minute (U/mg protein). OGDH activity was defined as the amount of enzyme that produces $1 \mathrm{nmol}$ of $\mathrm{NADH}$ per minute (U/mg protein). Measurements were performed at $595 \mathrm{~nm}$ using three replicates for each sample. 


\section{Statistical Analysis}

All experiments were repeated three times. Mean values and standard deviations were calculated using Excel 2010 (Microsoft Inc., Seattle, WA, USA). Statistical analyses were performed using one-way ANOVA with SPSS Statistics 17.0 (SPSS Inc., Chicago, USA).

\section{RESULTS}

\section{Identification of $B$. cinerea Proteins by ITRAQ}

A total of 204,639 spectra were generated by iTRAQ proteomic analysis using control and TTO-treated B. cinerea and were analyzed using the Mascot search engine. As shown in Figure 1A, 17,337 spectra matched known spectra, comprising 10,001 peptides, 9,720 unique peptides, and 2,397 proteins from control and TTO-treated samples. The distribution of the number of peptides, predicted molecular weights, and isoelectric points, and peptide sequence coverage are shown in Figures 1B-D, respectively. Over $87 \%$ of the proteins were represented by at least two peptides. Molecular weights ranged from 20 to $200 \mathrm{kDa}$, and isoelectric points ranged from 5.0 and 7.0. Approximately $51 \%$ of identified proteins had more than $10 \%$ peptide sequence coverage.

\section{Identification of Differentially Expressed Proteins Using ITRAQ}

The threshold for differential expression (TTO-treated vs. control) was a protein level difference $>1.5$ or $<0.67$, with a $p<0.05$. 718 differentially expressed proteins were identified in the TTO sample, of which 17 were up-regulated and 701 were down-regulated. Details for each protein are provided in Table 1.

\section{GO Analysis of DEPs}

GO analysis was conducted to identify significantly enriched GO functional groups. DEPs were categorized by biological process, cellular component, and molecular function. Of the 718 DEPs, 562 were annotated and classified into 30 functional groups (Figure 2). Biological processes accounted for $12 \mathrm{GO}$ terms (with "metabolic process" accounting for $44.11 \%$ of these, and "cellular process" 34.32\%). Cellular components accounted for 7 GO terms, dominated by "cell" (31.60\%) and "cell part" (31.60\%). Molecular functions accounted for 11 GO terms, the most abundant being "catalytic" (44.72\%) and "binding" (43.61\%).

The agriGO analysis tool was used to detect and visualize significantly enriched GO terms associated with the 562 annotated proteins, with an adjusted p-value cutoff of 0.05 . Significant functions included "regulation of biological quality" (GO:0065008, $p=0.033$ ) and "primary metabolic process" (GO:0044238, $p=0.016$ ). There are $5 \mathrm{DEPs}$, accounting for about $45.45 \%$ of the total protein in regulation of biological quality. And 189 DEPs, accounting for about $73.82 \%$ of the total protein in primary metabolic process.

\section{KEGG Analysis of DEPs}

Proteins typically do not exercise their functions independently, but coordinate with each other to complete a series of biochemical reactions. Pathway analysis can help reveal cellular processes involved in disease mechanisms or drug action. Using the KEGG database as a reference, 562 DEPs were linked to 133 different pathways. Glycolysis, the TCA cycle, and purine metabolism were among the pathways most significantly altered by exposure to TTO.

\section{Confocal Microscopy}

Confocal laser scanning microscopy was used to investigate $B$. cinerea cell membrane integrity after TTO treatment. PI easily penetrates a membrane-damaged cell and binds to DNA, resulting in red fluorescence. B. cinerea cells were examined by both bright-field microscopy (Figures 3A,C) and fluorescence microscopy (Figures 3B,D). Control cells have no detectable red fluorescence (Figure 3B), indicating that they have intact cell membranes. In contrast, red fluorescence was observed after cells were treated for $2 \mathrm{~h}$ with TTO at $5 \mathrm{~mL} / \mathrm{L}$ (Figure 3D). These results suggest that TTO compromises the integrity of the $B$. cinerea cell membrane, potentially causing cell death.

\section{Enzyme Activities Related to TCA Cycle}

Because the iTRAQ analysis clearly implicated the TCA cycle as a possible TTO target, we investigated the activities of $\mathrm{MDH}$, $\mathrm{CS}$, and OGDH, three key enzymes related to the TCA cycle (Figure 4). The results indicate that activities for these enzymes decreased significantly in TTO-treated cells $(87.4,53.3$, and $40.3 \%$, respectively), consistent with our observation that the $\mathrm{MDH}, \mathrm{CS}$, and OGDH proteins are significantly down-regulated in TTO-treated cells.

\section{DISCUSSION}

The antifungal activity of essential oils is probably based on their ability to significantly reduce total lipid and ergosterol content, thereby disrupting membrane permeability and resulting in leakage of cell components such as ATP, DNA, and potassium ions (Tian et al., 2011; Tao et al., 2014; Cui et al., 2015). Our previous study demonstrated that TTO considerably increases membrane permeability, causing extrusion of abundant material (Shao et al., 2013b; Yu et al., 2015) and decreasing intracellular ATP in B. cinerea (Li et al., 2017b). In this study, observations using confocal laser scanning microscopy indicate that TTO damages the $B$. cinerea cell membrane, potentially causing the release of internal material such as ATP.

Levels for many DEPs related to glycolysis metabolism, such as glucose-6-phosphate isomerase, 6-phosphofructokinase, phosphoenolpyruvate carboxykinase, fructose-1, 6bisphosphatase, and enolase, are decreased by TTO treatment (Table 1). Glucose-6-phosphate isomerase catalyzes the conversion of glucose-6-phosphate into fructose 6-phosphate 


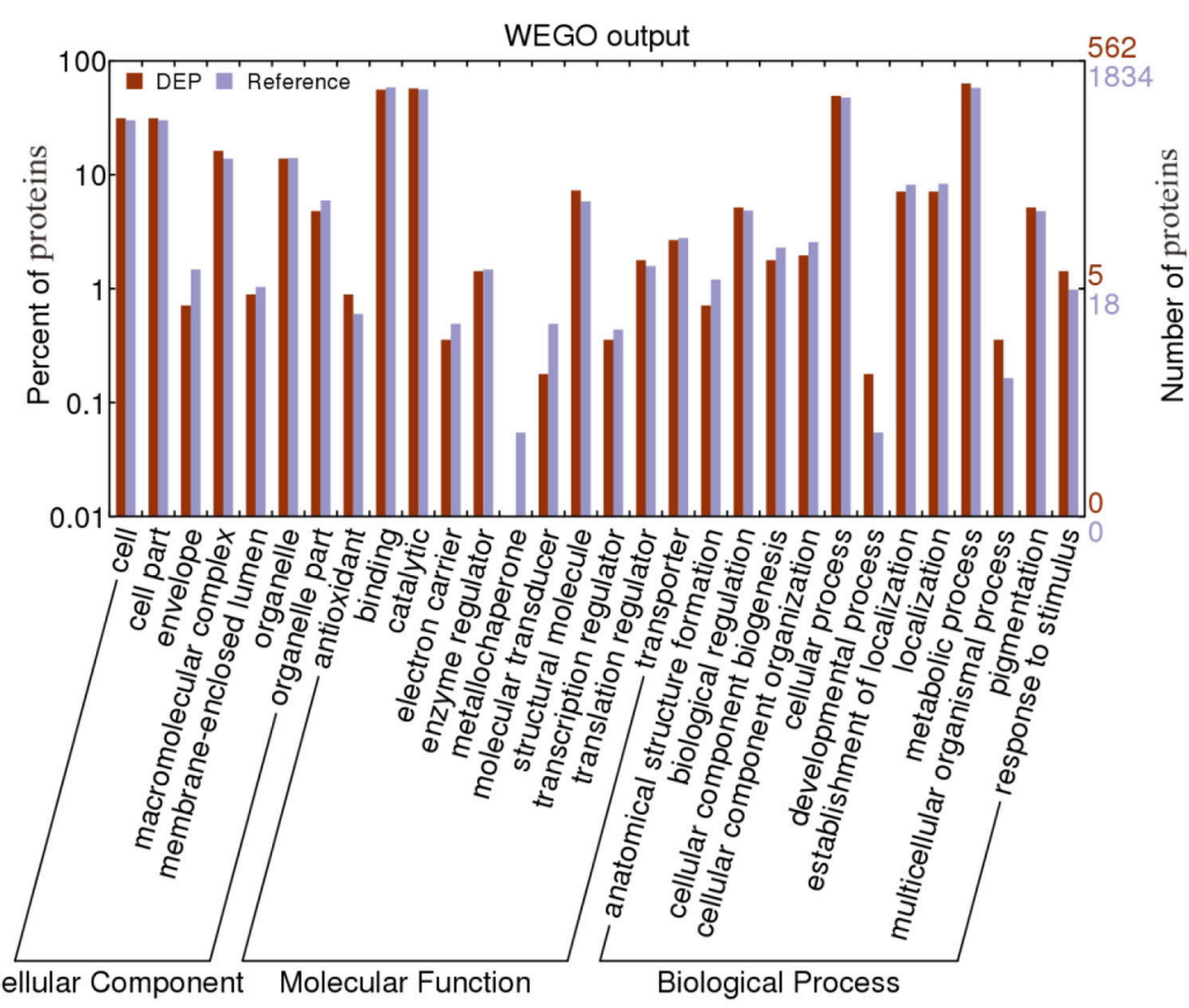

FIGURE 2 | Gene Ontology (GO) analysis of differentially expressed proteins (DEPs) identified in B. cinerea cells treated with TTO.

in the second step of glycolysis (Achari et al., 1981). 6phosphofructokinase is a key enzyme in the control of the glycolytic pathway in nearly all cells (Wang et al., 2016). The activity of this enzyme is controlled by several metabolites, most notably its two substrates, fructose 6-phosphate and ATP. Glycolysis is also an important pathway for energy production in the cytosol of plant cells. Our results suggest that TTO inhibits glycolysis and may affect energy supply in $B$. cinerea.

Mitochondria are the primary sites of aerobic respiration in eukaryotic cells. They generate energy for cellular functions through oxidative phosphorylation and the TCA cycle, and also play a crucial role in regulating the apoptosis (Shaughnessy et al., 2014). In this study, several proteins associated with the mitochondrial respiratory chain and TCA cycle, such as ATP synthase D chain, ATP synthase subunit e, MDH, $\mathrm{CS}$, and OGDH, were significantly down-regulated in cells treated with TTO (Table 1). ATP synthase D chain and ATP synthase subunit e are involved in the biosynthesis of ATP. Dill oil inhibits mitochondrial ATPase activity and dehydrogenase activities, and affects mitochondrial function in Aspergillus flavus (Tian et al., 2012). Mustard essential oils decrease intracellular ATP and increase extracellular ATP in E. coli O157:H7 and Salmonella typhi (Turgis et al., 2009). Citral decreases intracellular ATP content, increases extracellular ATP content, inhibits the TCA pathway, and decreases the activities of
CS and $\alpha$-ketoglutarate dehydrogenase in Penicillium digitatum (Zheng et al., 2015). Our additional study demonstrates that TTO treatment significantly inhibits the activities of $\mathrm{MDH}, \mathrm{CS}$, and $\mathrm{OGDH}$ (Figure 4). In our previous study, we found that TTO decreases intracellular ATP and the activities of MDH, succinate dehydrogenase, ATPase, CS, isocitrate dehydrogenase, and $\alpha$-ketoglutarate dehydrogenase, disrupting the TCA cycle in B. cinerea ( $\mathrm{Li}$ et al., 2017b). The down-regulation of two MDHs suggests that the Krebs cycle is not completely functional in Paracoccidioides lutzii upon exposure to argentilactone (Prado et al., 2014). Together, these results imply that TTO affects proteins in $B$. cinerea involved in glycolysis, the TCA cycle, and ATP synthesis, thereby disrupting the TCA cycle, interrupting energy metabolism, and inducing mitochondrial dysfunction.

Cytochrome c (cyt c) is a hemoglobin located in the inner mitochondrial membrane, and is responsible for transferring electrons between mitochondrial electron transport chain complexes III and IV (Reed, 1997; Lo et al., 2017). ATP is produced by the aerobic mitochondrial respiratory chain. Abnormal cyt $c$ disrupts the mitochondrial respiratory chain and impacts ATP production (Zhou et al., 2015). Our study shows that cyt $\mathrm{c}$ is up-regulated in $B$. cinerea after TTO treatment at $5 \mathrm{~mL} / \mathrm{L}$ (Table 1). The increase in cyt c levels may improve the performance of the oxidative 

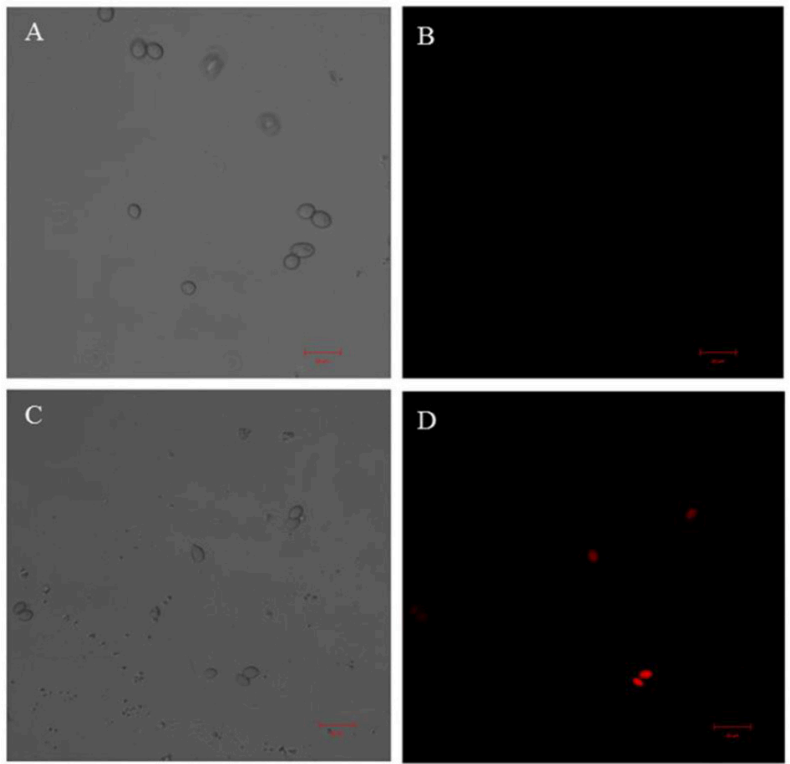

FIGURE 3 | Effect of TTO treatment on cytoplasmic membranes in B. cinerea cells. Images were acquired by confocal microscopy using the fluorescent indicator PI. B. cinerea spores were incubated without TTO (A,B), or with 5 $\mathrm{mL} / \mathrm{L} T \mathrm{TO}(\mathbf{C}, \mathbf{D})$. Bright-field $\mathbf{( A , C )}$ and fluorescent $\mathbf{( B , D )}$ images are shown. Red fluorescence indicates PI staining of nucleic acids. Scale bar: $20 \mu \mathrm{m}$.

respiratory chain, perhaps as a protective response to TTO toxicity.

Purines are one of the building blocks for nucleic acids. Their synthesis pathways generate many kinds of energy molecules (Qian et al., 2014). Inosine 5'-monophosphate dehydrogenase (IMPDH) is a rate-controlling enzyme in the de novo synthesis of the guanine nucleotide, and plays crucial roles in cell growth and proliferation (Fotie, 2016). IMPDH inhibition reduces guanine nucleotide pools and interrupts cellular functions such as DNA replication, RNA synthesis, and signal transduction (Weber, 1983; Weber et al., 1996). These effects are associated with cell cycle disruption, cellular differentiation, and apoptosis (Vitale et al., 1997; Yalowitz and Jayaram, 2000). Nucleoside diphosphate kinases (NDPK) are critical enzymes related to the maintenance of intracellular nucleotide levels, and catalyze the conversion of nucleoside triphosphates to nucleoside diphosphates in all living organisms (Véron et al., 1994). Both NDPK and AK can mediate the conversion of adenosine into ATP by ADP and AMP (Senft and Crabtree, 1983). In our study, TTO treatment decreased IMPDH levels (Table 1). Furthermore, levels of adenosine kinase AK and NDPK were also reduced after TTO treatment (Table 1). From these results, we can conclude that TTO may block the accumulation of energy and disrupt the cell cycle, ultimately inducing apoptosis.

\section{CONCLUSION}

The effect of TTO treatment on proteins in $B$. cinerea is summarized in Figure 5. We found that important metabolic
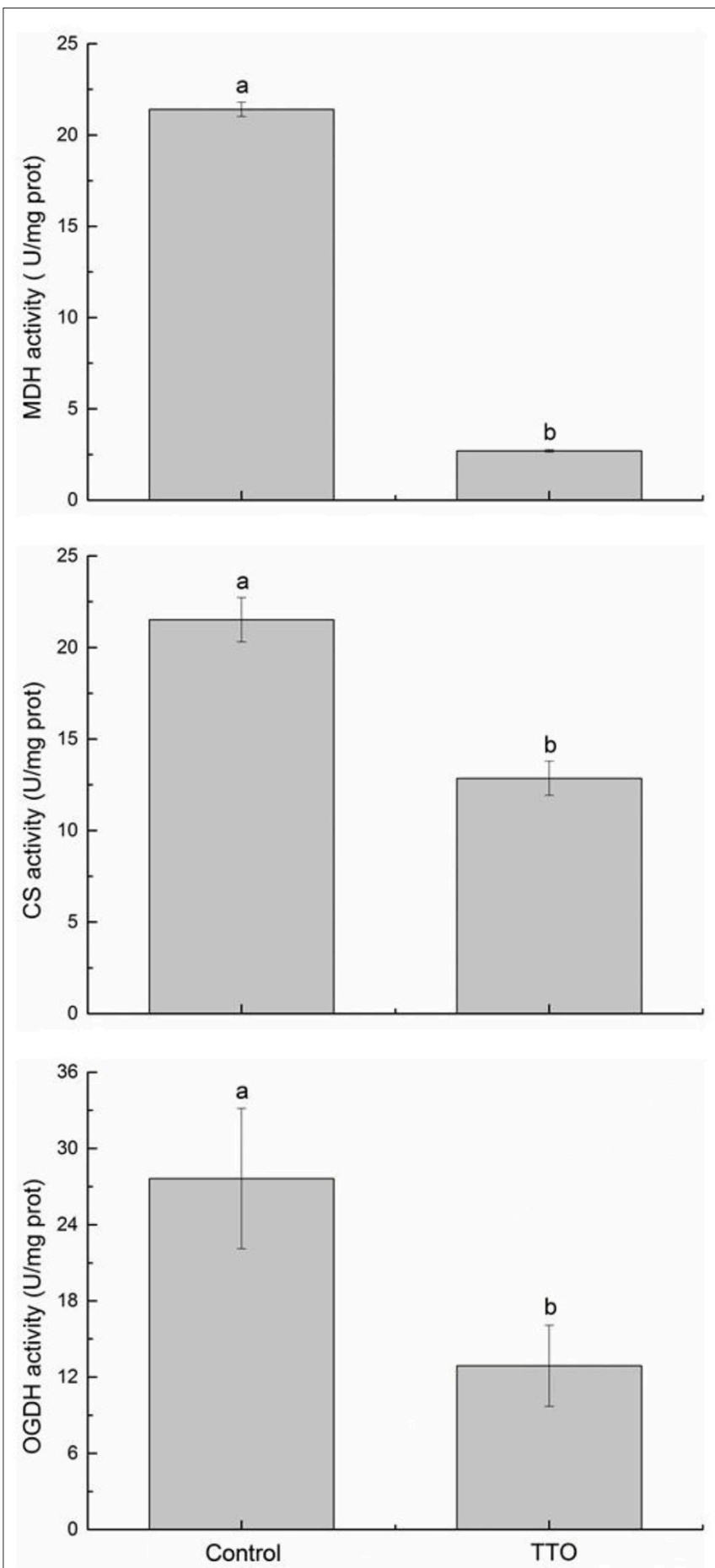

FIGURE 4 | Effect of TTO treatment on MDH, CS, and OGDH activities in B. cinerea. Vertical bars represent the standard deviation of the means. a,b: significant differences at $P<0.05$ level based on Duncan's multiple range tests.

pathways, including glycolysis, the TCA cycle, and purine metabolism, were compromised by TTO treatment, while cyt $c$ increased. We conclude that the disruption of energy 


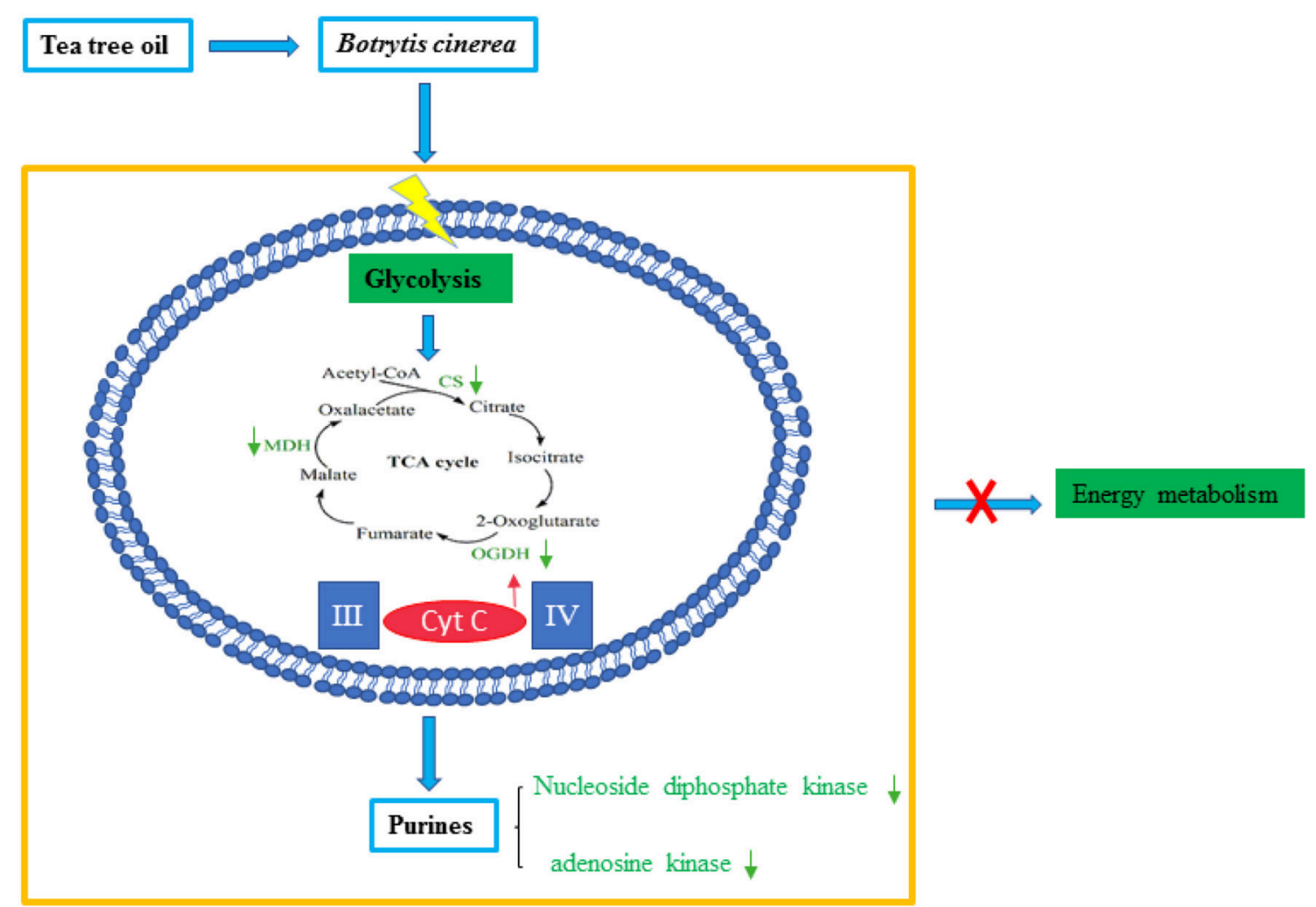

FIGURE 5 | Model summarizing antifungal effects of $Т \mathrm{O}$ in B. cinerea. Green arrows indicate down-regulation and red arrows indicate up-regulation.

metabolism by TTO contributes to its antifungal activity against B. cinerea.

\section{AUTHOR CONTRIBUTIONS}

JX and XS designed the experiments. JX and YW performed the experiments. FX and HW analyzed the data. JX, XS, and HW drafted the manuscript. All authors read and approved the final manuscript.

\section{REFERENCES}

Abdulazeez, M. A., Abdullahi, A. S., and James, B. D. (2016). "Chapter 58 Lemongrass (Cymbopogon spp.) Oils," in Essential Oils in Food Preservation Flavor and Safet (London, UK: Academic Press Books-Elsevier), 509-516.

Achari, A., Marshall, S. E., Muirhead, H., Palmieri, R. H., and Noltmann, E. A. (1981). Glucose-6-phosphate isomerase. Philos. Trans. R. Soc. London. 293, 145-157. doi: 10.1098/rstb.1981.0068

Ashburner, M., Ball, C. A., Blake, J. A., Botstein, D., Butler, H., Cherry, J. M., et al. (2000). Gene Ontology: tool for the unification of biology. Nat. Genet. 25, 25-29. doi: 10.1038/75556

Bona, E., Cantamessa, S., Pavan, M., Novello, G., Massa, N., Rocchetti, A., et al. (2016). Sensitivity of Candida albicans to essential oils: are they an alternative to antifungal agents? J. Appl. Microbiol. 121, 1530-1545. doi: 10.1111/jam.13282

Bradford, M. (1976). A rapid and sensitive method for the quantitation of microgram quantities of protein utilizing the principle of protein-dye binding. Anal. Biochem. 6, 3171-3188. doi: 10.1016/0003-2697(76)90527-3

\section{ACKNOWLEDGMENTS}

This study was funded by the National Science Foundation of China (No. 31371860), the Public Welfare Applied Research Project of Zhejiang Province (No. 2017C32010), the Science and Technology Program of Ningbo City (2017C10065), the School Research Project (XYL17014), and the K.C. Wong Magna Fund in Ningbo University.

Brul, S., and Coote, P. (1999). Preservative agents in foods: mode of action and microbial resistance mechanisms. Int. J. Food Microbiol. 50, 1-17. doi: 10.1016/S0168-1605(99)00072-0

Carson, C. F., Hammer, K. A., and Riley, T. V. (2006). Melaleuca alternifolia (Tea Tree) oil: a review of antimicrobial and other medicinal properties. Clin. Microbiol. Rev. 19, 50-62. doi: 10.1128/CMR.19.1.5062.2006

Cho, Y. S., and Oh, K. H. (2011). Cellular and proteomic responses of Escherichia coli JK-17 exposed to the Rosa hybrida flower extract. Biotechnol. Bioprocess Eng. 16, 885-893. doi: 10.1007/s12257-011-0051-5

Cui, H., Zhang, X., Zhou, H., Zhao, C., and Lin, L. (2015). Antimicrobial activity and mechanisms of Salvia sclarea essential oil. Bot. Stud. 56, 16. doi: 10.1186/s40529-015-0096-4

Fotie, J. (2016). Inosine 5'-Monophosphate Dehydrogenase (IMPDH) as a potential target for the development of a new generation of antiprotozoan agents. Mini Rev. Med. Chem. doi: 10.2174/1389557516666160620065558. [Epub ahead of print]. 
Franco, C., Soares, R., Pires, E., Koci, K., Almeida, A. M., Santos, R., et al. (2013). Understanding regeneration through proteomics. Proteomics 13, 686-709. doi: 10.1002/pmic.201200397

Fraternale, D., Flamini, G., and Ricci, D. (2014). Essential oil composition of Angelica archangelica L. (Apiaceae) roots and its antifungal activity against plant pathogenic fungi. Plant Biosyst. 150, 558-563. doi: 10.1080/11263504.2014.988190

Gustafson, J., Liew, Y., Chew, S., Markham, J., Bell, H., Wyllie, S., et al. (1998). Effects of tea tree oil on Escherichia coli. Lett. Appl. Microbiol. 26, 194-198. doi: 10.1046/j.1472-765X.1998.00317.x

Homer, L. E., Leach, D. N., Lea, D., Lee, L. S., Henry, R. J., and Baverstock, P. R. (2000). Natural variation in the essential oil content of Melaleuca alternifolia Cheel (Myrtaceae). Biochem. Syst. Ecol. 28, 367-382. doi: 10.1016/S0305-1978(99)00071-X

Kovács, J. K., Felso, P., Makszin, L., Pápai, Z., Horváth, G. Á. H., et al. (2016). Antimicrobial and virulence modulating effect of clove essential oil on the foodborne pathogen Campylobacter jejuni. Appl. Environ. Microbiol. 82, 6158-6166. doi: 10.1128/AEM.01221-16

Lee, H. S., and Kim, Y. (2017). Paeonia lactiflora inhibits cell wall synthesis and triggers membrane depolarization in Candida albicans. J. Microbiol. Biotechnol. 27, 395-404. doi: 10.4014/jmb.1611.11064

Leroux, P., Fritz, R., Debieu D., Albertini, C., Lanen, C., Bach, J., et al. (2002). Mechanisms of resistance to fungicides in field strains of Botrytis cinerea. Pest Manag. Sci. 58, 876-888. doi: 10.1002/ps.566

Li, Y., Shao, X., Xu, J., Wei, Y., Xu, F., and Wang, H. (2017a). Effects and possible mechanism of tea tree oil against Botrytis cinerea and Penicillium expansum in vitro and in vivo test. Can. J. Microbiol. 63, 219-227. doi: 10.1139/cjm-2016-0553

Li, Y., Shao, X., Xu, J., Wei, Y., Xu, F., and Wang, H. (2017b). Tea tree oil exhibits antifungal activity against Botrytis cinerea by affecting mitochondria. Food Chem. 234, 62-67. doi: 10.1016/j.foodchem.2017.04.172

Liu, S., Shao, X., Wei, Y., Li, Y., Xu, F., and Wang, H. (2016). Solidago canadensis L. essential oil vapor effectively inhibits Botrytis cinerea growth and preserves postharvest quality of strawberry as a food model system. Front. Microbiol. 7:1179. doi: $10.3389 /$ fmicb.2016.01179

Lo, Y. T., Huang, H., W., Huang, Y. C., Chan, J. F., and Hsu, Y. H. (2017). Elucidation of tRNA-cytochrome $\mathrm{c}$ interactions through hydrogen/deuterium exchange mass spectrometry. BBA Proteins Proteom. 1865, 539-546. doi: 10.1016/j.bbapap.2017.02.015

Miao, L., Zhu, L., Liu, B., Du, L., Jia, X., Li, H., et al. (2016). Tea tree oil nanoemulsions for inhalation therapies of bacterial and fungal pneumonia. Colloids. Surface. B. Biointerfaces 141, 408-416. doi: 10.1016/j.colsurfb.2016.02.017

Prado, R. S., Bailão, A., M., Silva, L. C., Oliveira, C. M. A. D., and Marques, M. F., Silva, L. P., et al. (2014). Proteomic profile response of Paracoccidioides lutzii to the antifungal argentilactone. Front. Microbiol. 6:616. doi: 10.3389/fmicb.2015.00616

Prakash, B., Singh, P., Kedia, A., and Dubey, N. K. (2012). Assessment of some essential oils as food preservatives based on antifungal, antiaflatoxin, antioxidant activities and in vivo efficacy in food system. Food Res. Int. 49, 201-208. doi: 10.1016/j.foodres.2012.08.020

Qian, Z., Liu, Z. L., Kang, N., Wang, A., Zeng, X., and Jian, X. (2014). Genomic and transcriptome analyses reveal that MAPK- and phosphatidylinositol-signaling pathways mediate tolerance to 5-hydroxymethyl-2-furaldehyde for industrial yeast Saccharomyces cerevisiae. Sci. Rep. 4:6556. doi:10.1038/srep06556

Reed, J. C. (1997). Cytochrome c: can't live with it-can't live without it. Cell 91, 559-562. doi: 10.1016/S0092-8674(00)80442-0

Senft, A. W., and Crabtree, G. W. (1983). Purine metabolism in the schistosomes: potential targets for chemotherapy. Pharmacol. Ther. 20, 341-356. doi: 10.1016/0163-7258(83)90031-1

Shao, X., Cheng, S., Wang, H., Yu, D., and Mungai, C. (2013b). The possible mechanism of antifungal action of tea tree oil on Botrytis cinerea. J. Appl. Microbiol. 114, 1642-1649. doi: 10.1111/jam.12193

Shao, X., Wang, H., Xu, F., and Cheng, S. (2013a). Effects and possible mechanisms of tea tree oil vapor treatment on the main disease in postharvest strawberry fruit. Postharvest Biol. Tec. 77, 94-101. doi: 10.1016/j.postharvbio.2012.11.010
Shaughnessy, D. T., McAllister, K., Worth, L., Haugen, A. C., Meyer, J. N., Domann, F. E., et al. (2014). Mitochondria, energetics, epigenetics, and cellular responses to stress. Environ. Health. Perspect. 122, 1271-1278. doi: 10.1289/ehp.1408418

Soylu, E. M., Kurt, S., and Soylu, S. (2010). In vitro and in vivo antifungal activities of the essential oils of various plants against tomato grey mould disease agent Botrytis cinerea. Int. J. Food Microbiol. 143, 183-189. doi: 10.1016/j.ijfoodmicro.2010.08.015

Tao, N., OuYang, Q., and Jia, L. (2014). Citral inhibits mycelial growth of Penicillium italicum by a membrane damage mechanism. Food Control 41, 116-121. doi: 10.1016/j.foodcont.2014.01.010

Tian, J., Ban, X., Zeng, H., He, J., Chen, Y., and Wang, Y. (2012). The mechanism of antifungal action of essential oil from dill (Anethum graveolens L.) on Aspergillus flavus. PLoS ONE 7:e30147. doi: 10.1371/journal.pone.0030147

Tian, J., Ban, X., Zeng, H., Huang, B., He, J., and Wang, Y. (2011). In vitro and in vivo activity of essential oil from dill (Anethum graveolens $\mathrm{L}$.) against fungal spoilage of cherry tomatoes. Food Control 22, 1992-1999. doi: 10.1016/j.foodcont.2011.05.018

Turgis, M., Han, J. J., Caillet, S., and Lacroix, M. (2009). Antimicrobial activity of mustard essential oil against Escherichia coli O157:H7 and Salmonella typhi. Food Control 20, 1073-1079. doi: 10.1016/j.foodcont.2009.02.001

Véron, M., Tepper, A., Hildebrandt, M., Lascu, I., Lacombe, M. L., Janin, J., et al. (1994). Nucleoside diphosphate kinase: an old enzyme with new functions? Adv. Exp. Med. Biol. 370, 607-611. doi: 10.1007/978-1-4615-2584-4_126

Vitale, M., Zamai, L., Falcieri, E., Zauli, G., Gobbi, P., Santi, S., et al. (1997). IMP dehydrogenase inhibitor, tiazofurin, induces apoptosis in K562 human erythroleukemia cells. Cytometry 30, 61-66. doi: 10.1002/(SICI)1097-0320(19970215)30:1<61::AID-CYTO9>3.0.CO;2-I

Wang, J., Zhang, P., Zhong, J., Tan, M., Ge, J., Tao, L., et al. (2016). The platelet isoform of phosphofructokinase contributes to metabolic reprogramming and maintains cell proliferation in clear cell renal cell carcinoma. Oncotarget 7 , 27142-27157. doi: 10.18632 /oncotarget. 8382

Weber, G. (1983). Enzymes of purine metabolism in cancer. Clin. Biochem. 16, 57-63. doi: 10.1016/S0009-9120(83)94432-6

Weber, G., Prajda, N., Yang, H., Yeh, Y. A., Shen, F., Singhal, R. L., et al. (1996). Current issues in the regulation of signal transduction. Adv. Enzyme Regul. 36, 33-55. doi: 10.1016/0065-2571(96)00003-9

Xu, J., Shao, X., Li, Y., Wei, Y., Xu, F., and Wang, H. (2017). Metabolomic analysis and mode of action of metabolites of tea tree oil involved in the suppression of Botrytis cinerea. Front. Microbiol. 8:1017. doi: 10.3389/fmicb.20 17.01017

Yalowitz, J. A., and Jayaram, H. N. (2000). Molecular targets of guanine nucleotides in differentiation, proliferation and apoptosis. Anticancer Res. 20, 2329-2338.

Yu, D., Wang, J., Shao, X., Xu, F., and Wang, H. (2015). Antifungal modes of action of tea tree oil and its two characteristic components against Botrytis cinerea. J. Appl. Microbiol. 119, 1253-1262. doi: 10.1111/jam.12939

Zheng, S., Jing, G., Wang, X., Ouyang, Q., Jia, L., and Tao, N. (2015). Citral exerts its antifungal activity against Penicillium digitatum by affecting the mitochondrial morphology and function. Food Chem. 178, 76-81. doi: 10.1016/j.foodchem.2015.01.077

Zhou, M., Li, Y., Hu, Q., Bai, X. C., Huang, W., Yan, C., et al. (2015). Atomic structure of the apoptosome: mechanism of cytochrome c- and dATP-mediated activation of Apaf-1. Genes Dev. 29, 2349-2361. doi: 10.1101/gad.272278.115

Zhou, Y., and Chen, W. N. (2011). iTRAQ-coupled 2-D LC-MS/MS analysis of membrane protein profile in Escherichia coli incubated with apidaecin IB. PLoS ONE 75:e20442. doi: 10.1371/journal.pone.0020442

Conflict of Interest Statement: The authors declare that the research was conducted in the absence of any commercial or financial relationships that could be construed as a potential conflict of interest.

Copyright $\odot 2017 \mathrm{Xu}$, Shao, Wei, Xu and Wang. This is an open-access article distributed under the terms of the Creative Commons Attribution License (CC BY). The use, distribution or reproduction in other forums is permitted, provided the original author(s) or licensor are credited and that the original publication in this journal is cited, in accordance with accepted academic practice. No use, distribution or reproduction is permitted which does not comply with these terms. 